\title{
Functional divergence in heat shock response following rapid speciation of Fucus spp. in the Baltic Sea
}

\author{
Asunción Lago-Lestón · Catarina Mota • \\ Lena Kautsky · Gareth A. Pearson
}

Received: 20 July 2009/ Accepted: 12 November 2009

(C) Springer-Verlag 2009

\begin{abstract}
In the Baltic Sea, the broadly distributed brown alga Fucus vesiculosus coexists in sympatry over part of its range (south west Gulf of Bothnia) with the Baltic endemic $F$. radicans sp. nov, while further north in colder and lower-salinity areas of the Baltic $F$. radicans occurs alone (north west Gulf of Bothnia). F. radicans appears to have arisen via rapid speciation from $F$. vesiculosus within the recent history of the Baltic (ca. $7500 \mathrm{BP}$ ). Possible functional divergence between the two species was investigated by comparing stress-responsive gene expression in a common-garden experiment. The experiment used two allopatric populations of Fucus vesiculosus from the Skagerrak (North Sea) and Central Baltic, as well as $F$. radicans from the same Central Baltic site. The two species in sympatry displayed divergent heat shock responses, while $F$. vesiculosus populations from allopatric sites did not. F. radicans was more sensitive to heat shock at $25^{\circ} \mathrm{C}$, either alone or together with high irradiance and desiccation, than Baltic or Skagerrak $F$. vesiculosus. The results indicate that rapid functional divergence in the inducible heat shock response has occurred between sympatric species on a timescale of thousands of years.
\end{abstract}

Communicated by T. Reusch.

A. Lago-Lestón · C. Mota · G. A. Pearson $(\bowtie)$

Centro de Ciências do Mar, CIMAR-Laboratorio Associado,

Universidade do Algarve, Campus de Gambelas,

8005-139 Faro, Portugal

e-mail: gpearson@ualg.pt

L. Kautsky

Department of Botany, Stockholm University,

10691 Stockholm, Sweden

\section{Introduction}

The brackish Baltic Sea is a marginal environment for marine species, both geographically and environmentally (Johannesson and André 2006). Although its current postglacial marine-brackish phase is recent (ca. 7500 BP (Ignatius et al. 1981; Donner 1995), isolation near the geographical and physiological limits of a species' distribution may result in periods of accelerated evolution (Orr and Smith 1998; Thompson 1998). These characteristics make the Baltic extremely interesting for the study of adaptive responses of populations to environmental change (Pearson et al. 2000; Gabrielsen et al. 2002; Riginos and Cunningham 2005) and rapid speciation (van Oppen et al. 1995; Pereyra et al. 2009).

A new species, endemic to the Baltic, was recently described (Bergström et al. 2005) as Fucus radicans, previously considered a dwarf morphotype of $F$. vesiculosus, together with which it occurs in sympatry in the SW Gulf of Bothnia. Further north in the Gulf of Bothnia (northern Baltic) at salinities of $<5$ PSU $F$. radicans is the only fucoid present (Tatarenkov et al. 2005; Pereyra et al. 2009). Species status for $F$. radicans is based on genetic and morphological differentiation from sympatric $F$. vesiculosus, and a greater capacity for, and predominance of, clonal reproduction (Bergström et al. 2005; Tatarenkov et al. 2005). Although unresolved by phylogenetic analysis of mitochondrial sequences (Coyer et al. 2006), microsatellite analysis has recently demonstrated reproductive isolation and very recent divergence time estimates between $F$. radicans and $F$. vesiculosus, possibly within hundreds rather than thousands of years BP (Pereyra et al. 2009). Endemic $F$. radicans therefore represents a case of rapid speciation within the Baltic Sea during the recent postglacial Littorina Sea period (ca. 7500 BP) (Ignatius et al. 1981; Russell 1985). 
Decreasing sea surface temperature (SST) from the western to the northern Baltic (Siegel et al. 2006) has received less attention than salinity clines, despite the important role of thermal stress in marine biogeography (Somero 2005). While it has been established that extreme low salinity (3-4 PSU in the Gulf of Bothnia) has negative effects on fucoid reproductive ecology (Serrão et al. 1996; Serrão et al. 1999), gradients of both salinity and SST may affect broader distributional patterns of Fucus spp. in the Baltic. Divergent physiological tolerances to abiotic stressors (desiccation, freezing) were previously reported between Fucus vesiculosus populations from intertidal and Baltic habitats (Pearson et al. 2000). Based on these findings, rapid intraspecific population divergence for adaptive traits has already occurred over the brief evolutionary history of the Baltic Sea.

Here, we test for functional divergence between $F$. radicans and $F$. vesiculosus living in sympatry in the non-tidal central Baltic. A second allopatric population of F. vesiculosus from the intertidal North Sea (Skagerrak) was included for comparison of divergence within the F. vesiculosus lineage. The heat shock response (HSR) was compared by assessing heat shock protein (Hsp) gene expression following acclimation in a common-garden experiment. A moderate heat shock treatment was applied, and the effects of additional high light and desiccation stressors, more typical of intertidal habitats, were also assessed.

\section{Methods}

In the Baltic Sea (SW Gulf of Bothnia; ca. 5.5 psu salinity, no tides), individuals of $F$. vesiculosus and $F$. radicans were collected from shallow sympatric stands (1-2 m depth) at Öregrund (Fig. 1: $60^{\circ} 20^{\prime} \mathrm{N}, 18^{\circ} 26^{\prime} \mathrm{E}$ ). In the Skagerrak (20-30 PSU, tidal), an intertidal sample of F. vesiculosus was collected at Tjärnö on the Swedish west coast (Fig. 1: $58^{\circ} 52^{\prime} \mathrm{N}, 11^{\circ} 10^{\prime} \mathrm{E}$ ). Samples were collected at the end of June when the SST was similar at both areas, about $18^{\circ} \mathrm{C}$

Growing apices from random samples of ca. 20 individuals per population/species were cultured in salinityadjusted (5.5 PSU for Baltic populations) or filtered natural seawater (SW; 25-27 PSU) for $14-16$ days $\left(15^{\circ} \mathrm{C}\right.$, low photon flux density (PPFD) of $50 \mu \mathrm{mol} \mathrm{m}{ }^{-2} \mathrm{~s}^{-1}, 16: 8 \mathrm{~h}$ light:dark), to provide a common acclimation history (Pearson et al. 2000). Experimental treatments consisted of short-term $(30 \mathrm{~min})$ exposure to water and thermal stressors: (1) Control: $15^{\circ} \mathrm{C}$ and $50 \mu \mathrm{mol} \mathrm{m} \mathrm{m}^{-2} \mathrm{~s}^{-1}$, (2) High light: $15^{\circ} \mathrm{C}$ and $250 \mu \mathrm{mol} \mathrm{m}{ }^{-2} \mathrm{~s}^{-1}$, (3) Heat shock: $25^{\circ} \mathrm{C}$ and $50 \mu \mathrm{mol} \mathrm{m} \mathrm{m}^{-2} \mathrm{~s}^{-1}$, (4) Heat shock with high light: $25^{\circ} \mathrm{C}$ and $250 \mu \mathrm{mol} \mathrm{m}{ }^{-2} \mathrm{~s}^{-1}$, and (5) Heat shock with high

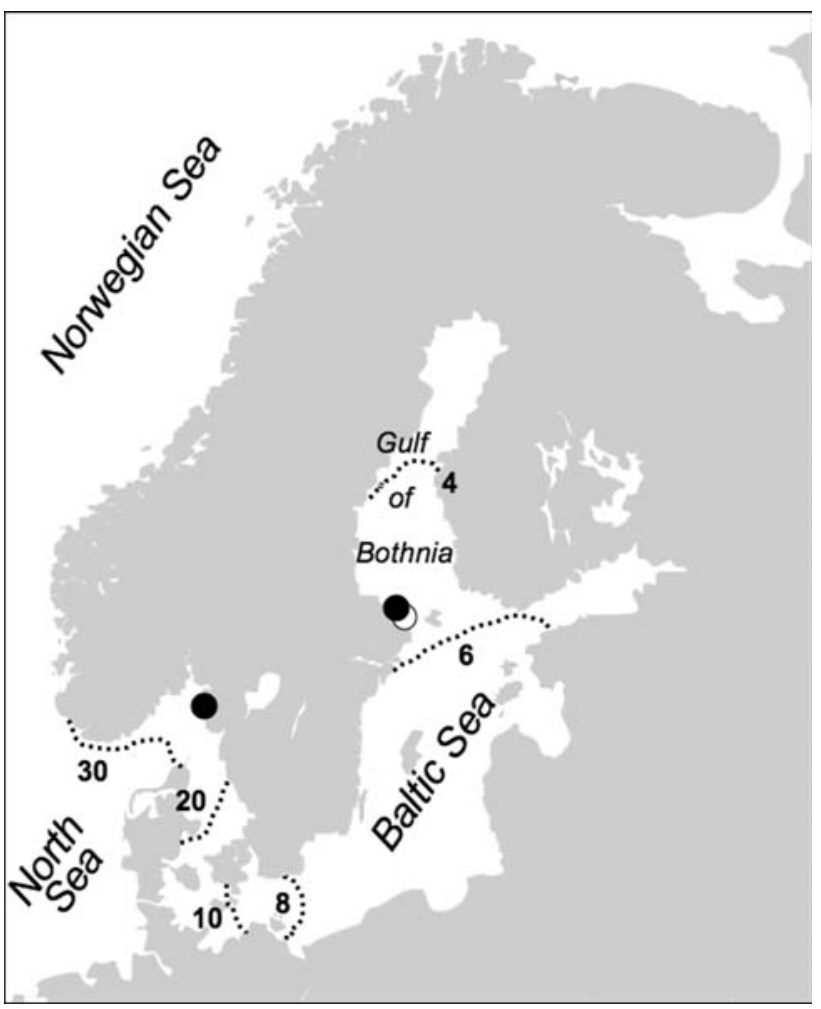

Fig. 1 Map of the Baltic-Skagerrak region showing sampling sites for $F$. vesiculosus (filled circles) and $F$. radicans (open circle). Isohalines (dotted lines) and salinities are shown

light and desiccation: aerial exposure at $25^{\circ} \mathrm{C}$ and $250 \mu \mathrm{mol} \mathrm{m} \mathrm{m}^{-2} \mathrm{~s}^{-1}$ (final tissue water content $60-70 \%$ that of hydrated tissue) Following the treatments, tissue was immediately frozen in liquid nitrogen and stored at $-80^{\circ} \mathrm{C}$ before being lyophilized in preparation for RNA extraction.

Total RNA was extracted from lyophilized samples following Pearson et al. (2006). RNA samples were treated with DNase I (Qiagen, Hilden, Germany) cleaned using RNeasy (Qiagen, Hilden, Germany), quantified by UV spectrophotometry, checked for integrity by agarose gel electrophoresis, and stored at $-80^{\circ} \mathrm{C}$. Total RNA $(2 \mu \mathrm{g})$ from a pool of ca. 20 individuals/treatment was reversetranscribed with SuperScript III RT (Invitrogen, Carlsbad, CA, USA) and oligo-dT(18) primer (MBI Fermentas, Heidelberg, Germany) in duplicate $20 \mu \mathrm{L}$ reactions that were then pooled. This was done to minimize possible effects of variations in cDNA synthesis reactions on qPCR. qPCR amplifications were run in triplicate (technical replicates) for each target and reference gene. The efficiency of PCR was calculated for the reference ( $\alpha$-tubulin) and each target gene, from triplicate amplifications of a dilution series $\left(10^{-1}, 10^{-2}\right.$, and $\left.10^{-3}\right)$, using as template pooled cDNA from all experimental conditions (Pfaffl et al. 2002). Efficiencies were calculated from the slope of the threshold cycle $(\mathrm{Ct})$ versus [cDNA] plot in the standard way from: 
$E=10^{-1 / \text { slope }}$

(Pfaffl et al. 2002), where $E=$ amplification efficiency between 1 (minimum) and 2 (theoretical maximum).

The following genes (GenBank accession numbers in parentheses) were selected from Fucus EST libraries (Pearson et al. 2009a): Hsp70 (EU780017) and Hsp90 (EU780016), two genes encoding sHsps; sHsp_5 (EU780019) and sHsp_n3 (EU780018), a putative late embryogenesis abundant (LEA) protein (EU780020), and a 14-3-3 protein (EU780021). Primers were designed using Primer3 (http://frodo.wi.mit.edu/) (Tm $68-70^{\circ} \mathrm{C}$; amplicon size 100-150 bp) (Table 1). Triplicate PCR per condition was performed in $20 \mu \mathrm{L}$ using SYBR green-based detection (BioRad, Hercules, California, USA), $1 \mu \mathrm{L}$ of cDNA $\left(10^{-1}\right.$ dilution) and $0.5 \mu \mathrm{M}$ per primer, on an iCycler iQ Detection System (BioRad, Hercules, California, USA). Cycle parameters were $95^{\circ} \mathrm{C}$ for 2 min and then 40 cycles at $95^{\circ} \mathrm{C}$ for $10 \mathrm{~s}$ and $68^{\circ} \mathrm{C}$ for $30 \mathrm{~s}$. Differences in relative gene expression between controls (acclimation conditions) and treatment means were assessed using randomization tests implemented with the REST $^{\odot}$ software of Pfaffl et al. (2002). Randomization tests have a similar power as standard parametric tests, but make no assumptions about the underlying distribution of the data, an advantage with relative gene expression data that are based on ratios.

\section{Results and discussion}

A divergent HSR was found for all four Hsp genes tested, with greater expression in $F$. radicans than $F$. vesiculosus
(Fig. 2a-d). The results reveal divergence between these species at a functional genomic level, even where they occur in mixed stands in the Central Baltic Sea, reinforcing current evidence for species differentiation (reproductive isolation, clonality, divergent morphology, and reproductive success; (Serrão et al. 1996, 1999; Bergström et al. 2005; Tatarenkov et al. 2005; Pereyra et al. 2009).

The HSR, where present, was broadly similar under heat shock with and without additional light and/or desiccation stressors. High light alone did not induce HSR (see below for sHsp down-regulation), thus the Hsp genes tested responded primarily to thermal stress under our experimental conditions, with no evidence for additive effects of high light and/or desiccation stressors. The heat shock temperature of $25^{\circ} \mathrm{C}$ was modest, only slightly above the maximum summer temperatures experienced by submerged Fucus in the Baltic (Siegel et al. 2006). Exposure time was kept short at 30 min to minimize chronic effects that might obscure regulatory differences in gene expression. Similar temperature conditions are regularly experienced by intertidal fucoid populations, even at these latitudes (Beer and Kautsky 1992), and can be greatly exceeded at other locations within the broad range of F. vesiculosus (Pearson et al. 2009b). The limited response of Hsp90 and Hsp70 in intertidal F. vesiculosus from the Swedish west coast was therefore unsurprising (Fig. 2a, b). Furthermore, the similarity between the responses of both F. vesiculosus populations (Skagerrak and Baltic) suggests that the HSR has probably not undergone evolutionary change at the level of gene expression in Baltic F. vesiculosus. However, this is in contrast to physiological responses to emersion-stress tolerance (freezing and

Table 1 Genbank accession number, annotations (Blastx top hit against SwissProt, unless indicated otherwise), and primer sequences used for qPCR of $F$. vesiculosus and F. radicans from Öregrund, Baltic Sea (F.ves(B), F.rad(B)), and Tjärnö, Skagerrak (F.ves(SK))

\begin{tabular}{|c|c|c|c|c|c|c|}
\hline \multirow[t]{2}{*}{ Name } & \multirow[t]{2}{*}{ Accession/SP Annotation } & \multirow[t]{2}{*}{ Primers $5^{\prime}-3^{\prime}$} & \multirow{2}{*}{$\begin{array}{l}\text { Amplicon } \\
\text { (bp) }\end{array}$} & \multicolumn{3}{|c|}{ PCR efficiency $(E)$} \\
\hline & & & & F.ves(SK) & F.ves(B) & F.rad(B) \\
\hline \multirow[t]{2}{*}{ Tub } & \multirow[t]{2}{*}{ Q40831/Tubulin alpha-1 chain } & F: CACGAATTGGATCGTGCGCTTG & 119 & 1.63 & 1.68 & 1.62 \\
\hline & & R: TACTTGCCGTGCCTAGGGTCGC & & $(0.109)$ & $(0.172)$ & $(0.155)$ \\
\hline \multirow[t]{2}{*}{ Hsp90 } & \multirow[t]{2}{*}{ EU780016/Heat shock protein 81-2 (HSP81-2) } & F: CGTGAAGGGCGTGGTGGACT & 140 & 1.71 & 1.71 & 1.65 \\
\hline & & R: CGTCCTCGGCAAGCTCGTTG & & $(0.177)$ & $(0.211)$ & $(0.188)$ \\
\hline \multirow[t]{2}{*}{ Hsp70 } & \multirow[t]{2}{*}{ EU780017/Heat shock $70 \mathrm{kDa}$ protein } & F: CGAAGGGCCAGATCCACGAG & 101 & 1.56 & 1.61 & 1.61 \\
\hline & & R: ACACGGCTCCTTGCCGTTGA & & $(0.133)$ & $(0.126)$ & $(0.172)$ \\
\hline \multirow[t]{2}{*}{ sHsp_n3 } & \multirow[t]{2}{*}{ EU780018/17.4 kDa class I heat shock protein 4} & F: TCCTTGCCTTTTGCGCGTTC & 119 & 1.71 & 1.80 & 1.60 \\
\hline & & R: ATCCCGTGGTTCCCGTCCTC & & $(0.206)$ & $(0.250)$ & $(0.140)$ \\
\hline \multirow[t]{2}{*}{ sHsp_5 } & \multirow[t]{2}{*}{ EU780019/18.0 kDa class I heat shock protein } & F: CAAGGTGGACATCGACAGCGAGT & 112 & 1.74 & 1.70 & 1.69 \\
\hline & & R: CACGAAGTGGTACTTGCGCTGCT & & $(0.175)$ & $(0.162)$ & $(0.086)$ \\
\hline \multirow[t]{2}{*}{$14-3-3$} & \multirow[t]{2}{*}{ EU780021/14-3-3-like protein } & F: TCGACGACGCAATCGCAGAG & 121 & 1.85 & 1.77 & 1.79 \\
\hline & & R: TCCGCCTCTCCCTGGTCTGA & & $(0.331)$ & $(0.217)$ & $(0.234)$ \\
\hline \multirow[t]{2}{*}{ LEA-like } & \multirow[t]{2}{*}{ EU780020/ ${ }^{\mathrm{a}}$ plant late embryo abundant related } & F: CCGCAGAGGAAGCCGATGAA & 147 & 1.46 & 1.46 & 1.55 \\
\hline & & R: TGACAGAGTTGGCGGCGTTG & & $(0.077)$ & $(0.084)$ & $(0.116)$ \\
\hline
\end{tabular}

The amplicon size and calculated PCR efficiency $( \pm$ SE) for each gene are also shown

a BLASTO top hit: blast to orthologous groups (Zhou and Landweber 2007) 

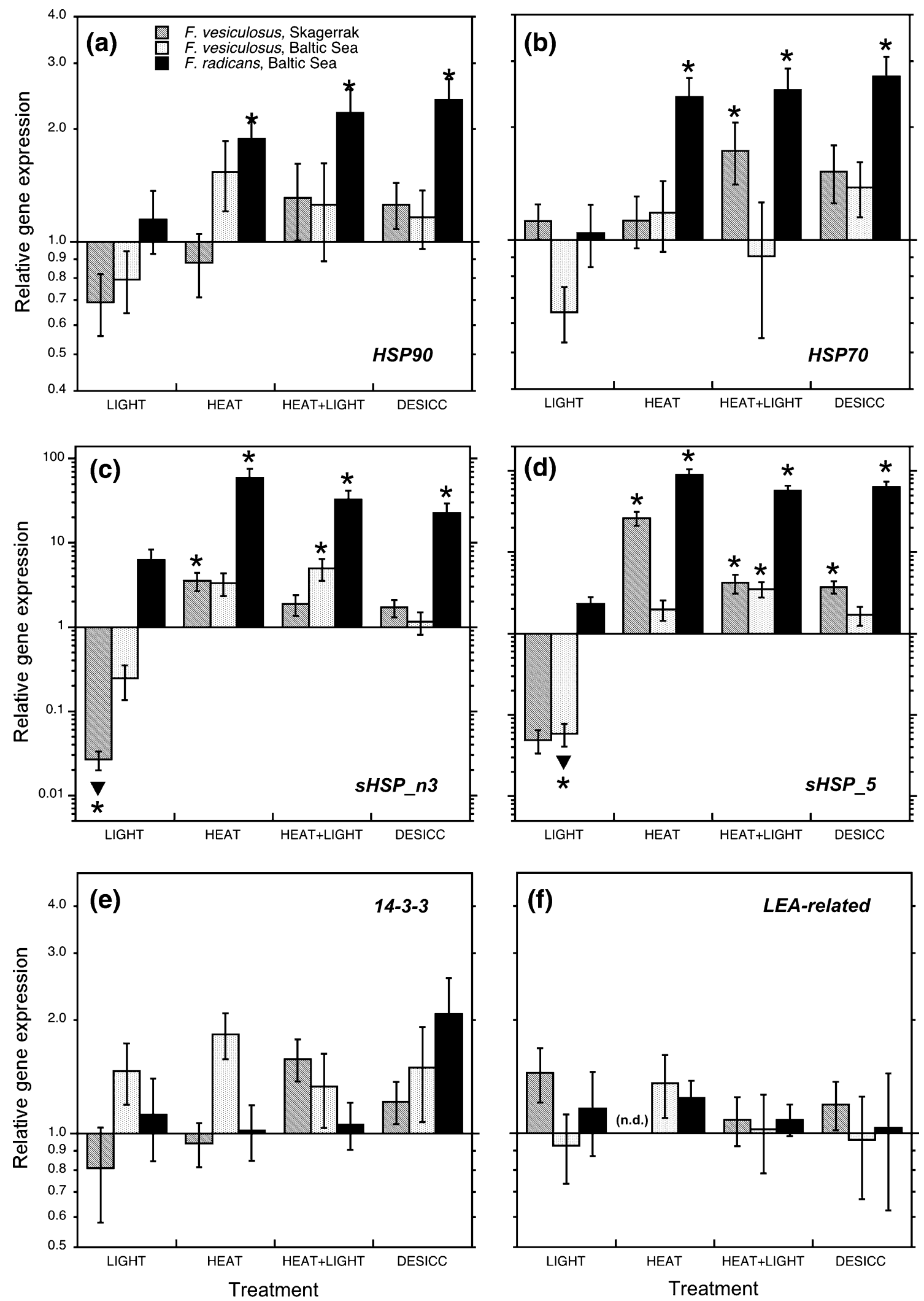

Fig. 2 Relative gene expression (fold change, mean \pm SE) after 30 min exposure to high light (LIGHT), heat shock at $25^{\circ} \mathrm{C}$ (HEAT), combined light and heat shock (HEAT + LIGHT), and desiccation under high light and heat shock (DESICC), in Skagerrak and Baltic
F. vesiculosus, and Baltic $F$. radicans for: a Hsp90, b Hsp70, c sHsp_3, d sHsp_5, e 14-3-3, and f LEA-like. Reference gene was $\alpha$-tubulin. Values are means $\pm \mathrm{SE}(n=3)$. Asterisks indicate treatments significantly different $(P<0.05)$ from control (acclimation) 
desiccation: Pearson et al. 2000), and longer term and/or exposure to more extreme temperatures will be required to clarify intraspecific variation in HSR.

While members of the Hsp90 and Hsp70 gene families have essential cellular functions and are constitutively expressed (Feder and Hofmann 1999; Frydman 2001), members of the small heat shock protein/ $\alpha$-crystallin family (sHsps) have protective roles (Lee and Vierling 2000; Laksanalamai and Robb 2004) and are transcriptionally regulated in response to HS and other stressors in plants (Waters et al. 1996). Our sHsp data revealed a hypersensitive HSR in $F$. radicans living in sympatry with $F$. vesiculosus. Two sHsp gene products were rapidly and highly over-expressed in $F$. radicans, between $>20$ and 100-fold within $30 \mathrm{~min}$ (Fig. 2c, d). In both F. vesiculosus populations (Skagerrak and Baltic), induction remained ca. an order of magnitude lower than for Baltic F. radicans. We thus show a clear species-specific difference in HSR. Few differences were detected between $F$. vesiculosus allopatric populations, although the response of sHsp_5 to HS deserves further attention.

The response of individual sHsp family members $(>10$ in Fucus based on EST data-Pearson et al. 2009a) would benefit from a more detailed characterization of expression under a variety of temperature and other abiotic conditions, and over a more extensive time-course. It is unclear why sHsp expression was down-regulated by high light in $F$. vesiculosus; a speculative hypothesis could be that higher photosynthetic rates increase ATP levels allowing (ATP-dependent) Hsp70-mediated refolding of non-native proteins, reducing the need for (ATP-independent) sHsp binding.

Two other transcripts were tested for their response to short-term stress exposure; a member of a multifunctional 14-3-3 protein family, which includes chaperone-type functions (Ferl et al. 2002), and a transcript with limited homology to a late embryogenesis abundant (LEA) protein. Under these experimental conditions, neither transcript significantly changed abundance (Fig. 2e, f).

Species distributions in the Baltic are often considered in the light of salinity gradients, but there is also an important gradient of average SST decreasing from the Gulf of Bothnia (mean SST of $7-8^{\circ} \mathrm{C}$ at the Central Baltic sympatric site and southern limit of $F$. radicans, Fig. 1) north into the Bothnian Bay (mean SST of $<5^{\circ} \mathrm{C}$ ). South of the Central Baltic sympatric site at Öregrund typical mean annual SST is fairly constant at $9-10^{\circ} \mathrm{C}$ (Siegel et al. 2006). The HSR of $F$. radicans suggests that thermal stress and/or growth temperature requirements could play a role in excluding this species from more southerly parts of the Baltic, restricting it to marginal habitats, where sexual reproduction (particularly male function) is compromised by low salinity conditions (Serrão et al. 1996, 1999), and clonal reproduction is an advantage (Tatarenkov et al. 2005).

Recent support for an evolutionary scenario in which $F$. radicans arose by rapid speciation from Baltic $F$. vesiculosus (Pereyra et al. 2009), as well as the lack of functional divergence between $F$. vesiculosus populations from the Baltic and Skagerrak shown here, implies that rapid evolution of the HSR regulatory machinery has occurred between Baltic $F$. vesiculosus and $F$. radicans. Although our understanding of the HSR in natural populations is limited, in low temperature environments the threshold temperature for heat shock is generally lower in comparison with those from higher or more variable thermal environments (reviewed by Feder and Hofmann 1999). For example, the HSR in Antarctic macroalgae can be induced at temperatures as low as $5^{\circ} \mathrm{C}$ (Vayda and Yuan 1994). The hypersensitive HSR of $F$. radicans may therefore be a consequence of a more cold-adapted physiology. A second possibility is that reduced tolerance to heat shock is a (nonadaptive) consequence of clonal reproduction and genomewide loss of genetic diversity near the range edge (Pearson et al. 2009b). Based on the data of Tatarenkov et al. (2005), it is likely that several of the $F$. radicans individuals used in this study were genetically identical clones, while clonality in $F$. vesiculosus is much lower, or absent, in Baltic and Skagerrak populations, respectively. These alternative hypotheses (adaptive divergence versus loss of functional genetic diversity) could be addressed by comparing the relationship between trait means and neutral genetic diversity in less (clonally reproducing) and more (sexually reproducing) genetically diverse populations of $F$. radicans from different areas of the Baltic Sea. Whatever the predominant evolutionary mechanism, the functional divergence of HSR, a fundamental cellular process, between recently diverged species in a marginal marine habitat is a novel observation with potentially significant implications for ecological, evolutionary, and conservation biology.

Acknowledgments This work was supported by funding from FCTFEDER (ADAPT-POCI-PPCDT/MAR/61105/2004), Portugal and the EU Network of Excellence Marine Genomics Europe (G.A.P.), and a PhD fellowship from FCT and ESF (A.L.). The authors are grateful to two anonymous reviewers for comments and suggestions that improved the manuscript.

\section{References}

Beer S, Kautsky L (1992) The recovery of net photosynthesis during rehydration of Botanica Marina three Fucus species from the Swedish west coast following exposure to air. 35:487-491

Bergström L, Tatarenkov A, Johannesson K, Jönsson RB, Kautsky L (2005) Genetic and morphological identification of Fucus radicans sp. nov. (Fucales, Phaeophyceae) in the brackish Baltic Sea. J Phycol 41:1025-1038. doi:10.1111/j.1529-8817.2005. 00125.x 
Coyer JA, Hoarau G, Secq M-PO-L, Stam WT, Olsen JL (2006) A mtDNA-based phylogeny of the brown algal genus Fucus (Heterokontophyta; Phaeophyta). Mol Phylogen Evol 39:209222. doi:10.1016/j.ympev.2006.01.019

Donner J (1995) The quaternary history of Scandinavia. Cambridge University Press, Cambridge

Feder ME, Hofmann GE (1999) Heat-shock proteins, molecular chaperones, and the stress response: evolutionary and ecological physiology. Annu Rev Physiol 61:243-282. doi:10.1146/ annurev.physiol.61.1.243

Ferl RJ, Manak MS, Reyes MF (2002) The 14-3-3s. Genome Biology 3: reviews3010.3011—reviews3010.3017. doi:10.1186/gb-20023-7-reviews 3010

Frydman J (2001) Folding of newly translated proteins in vivo: the role of molecular chaperones. Annu Rev Biochem 70:603-647. doi:10.1146/annurev.biochem.70.1.603

Gabrielsen TM, Brochmann C, Rueness J (2002) The Baltic Sea as a model system for studying postglacial colonization and ecological differentiation, exemplified by the red alga Ceramium tenuicorne. Mol Ecol 11:2083-2095. doi:10.1046/j.1365-294X. 2002.01601.x

Ignatius H, Axberg S, Niemistö L, Winterhalter B (1981) Quaternary geology of the Baltic Sea. In: Voipio A (ed) The Baltic Sea. Elsevier Scientific, Amsterdam, pp 54-104

Johannesson K, André C (2006) Life on the margin: genetic isolation and diversity loss in a peripheral marine ecosystem, the Baltic Sea. Mol Ecol 15:2013-2029. doi:10.1111/j.1365-294X.2006. 02919.x

Laksanalamai P, Robb FT (2004) Small heat shock proteins from extremophiles: a review. Extremophiles 8:1-11. doi:10.1007/ s00792-003-0362-3

Lee GJ, Vierling E (2000) A small heat shock protein cooperates with heat shock protein 70 systems to reactivate a heat-denatured protein. Plant Physiol 122:189-197

Orr MR, Smith TB (1998) Ecology and speciation. Trends Ecol Evol 13:502-506. doi:10.1016/S0169-5347(98)01511-0

Pearson GA, Kautsky L, Serrão E (2000) Recent evolution in Baltic Fucus vesiculosus: reduced tolerance to emersion stresses compared to intertidal (North Sea) populations. Mar Ecol Prog Ser 202:67-79. doi:10.3354/meps202067

Pearson GA, Lago-Leston A, Valente M, Serrão E (2006) Simple and rapid RNA extraction from freeze-dried tissue of brown algae and seagrasses. Eur J Phycol 41:97-104. doi:10.1080/ 09670260500505011

Pearson GA, Hoarau G, Lago-Leston A, Coyer JA, Kube M, Reinhardt R, Henckel K, Serrão ETA, Corre E, Olsen JL (2009a) An expressed sequence tag analysis of the intertidal brown seaweeds Fucus serratus (L.) and F. vesiculosus (L.) (Heterokontophyta, Phaeophyceae) in response to abiotic stressors. Mar Biotechnol

Pearson GA, Lago-Leston A, Mota C (2009b) Frayed at the edges: selective pressure and adaptive response to abiotic stressors are mismatched in low diversity edge populations. J Ecol 97:450 462. doi:10.1111/j.1365-2745.2009.01481.x

Pereyra RT, Bergström L, Kautsky L, Johannesson K (2009) Rapid speciation in a newly opened postglacial marine environment, the Baltic Sea. BMC Evol Biol 9:70. doi:10.1186/1471-21489-70

Pfaffl MW, Horgan GW, Dempfle L (2002) Relative expression software tool $\left(\operatorname{REST}^{\odot}\right)$ for group-wise comparison and statistical analysis of relative expression results in real-time PCR. Nucleic Acids Res 30:e36

Riginos C, Cunningham CW (2005) Local adaptation and species segregation in two mussel (Mytilus edulis $\times$ Mytilus trossulus) hybrid zones. Mol Ecol 14:381-400. doi:10.1111/j.1365-294X. 2004.02379.x

Russell G (1985) Recent evolutionary changes in the algae of the Baltic Sea. Br Phycol J 20:87-104. doi:10.1080/000716 18500650111

Serrão E, Kautsky L, Brawley SH (1996) Distributional success of the marine seaweed Fucus vesiculosus L. in the brackish Baltic sea correlates with osmotic capabilities of Baltic gametes. Oecologia 107:1-12

Serrão EA, Brawley SH, Hedman J, Kautsky L, Samuelsson G (1999) Reproductive success of Fucus vesiculosus (Phaeophyceae) in the Baltic Sea. J Phycol 35:254-269. doi:10.1046/j.1529-8817. 1999.3520254.x

Siegel H, Gerth M, Tschersich G (2006) Sea surface temperature development of the Baltic Sea in the period 1990-2004. Oceanologia 48:119-131

Somero GN (2005) Linking biogeography to physiology: evolutionary and acclimatory adjustments of thermal limits. Front Zool 2:1. doi:10.1186/1742-9994-2-1

Tatarenkov A, Bergström L, Jönsson RB, Serrão EA, Kautsky L, Johannesson K (2005) Intriguing asexual life in marginal populations of the brown seaweed Fucus vesiculosus. Mol Ecol 14:647-651. doi:10.1111/j.1365-294X.2005.02425.x

Thompson JN (1998) Rapid evolution as an ecological process. Trends Ecol Evol 13:329-332. doi:10.1016/S0169-5347(98) 01378-0

van Oppen MJH, Olsen JL, Stam WT (1995) Genetic variation within and among North Atlantic and Baltic populations of the benthic alga Phycodrus rubens (Rhodophyta). Eur J Phycol 30:251-260. doi:10.1080/09670269500651021

Vayda ME, Yuan ML (1994) The heat shock response of an Antarctic alga is evident at $5^{\circ} \mathrm{C}$. Plant Mol Biol 24:229-233. doi: 10.1007/BF00040590

Waters ER, Lee GJ, Vierling E (1996) Evolution, structure and function of the small heat shock proteins in plants. J Exp Biol 47:325-338

Zhou Y, Landweber LF (2007) BLASTO: a tool for searching orthologous groups. Nucleic Acids Res 35:W678-W682. doi: 10.1093/nar/gkm278 